\title{
CIÊNCIA E SOCIEDADE
}

Science and Society

Ciencia y Sociedad

Luís Eduardo Bovolato ${ }^{1}$, Raphael Sanzio Pimenta ${ }^{2}$, Guilherme Nobre Lima do Nascimento ${ }^{2}$, Renata Junqueira Pereira ${ }^{2}$

${ }^{1}$ Reitoria, Universidade Federal do Tocantins, Brasil.

${ }^{2}$ Pró-reitoria de Pesquisa e Pós-Graduação, Universidade Federal do Tocantins, Brasil.

*Correspondência: Pró-reitoria de Pesquisa e Pós-Graduação, Bloco 4, Sala 15, Av. NS 15, 109 Norte, Palmas, Tocantins, Brasil.CEP:77.010-090.E-mail:pibic@uft.edu.br

Publicado em 30/10/2020.

\section{EDITORIAL}

O conhecimento e a informação impactam significativamente na vida das comunidades e seu compartilhamento pode transformar as economias e as sociedades (PORTUGAL, 2018b).

Segundo a UNESCO, na sociedade o conhecimento é o principal recurso para criação de riqueza, prosperidade e bem estar para a população, e este tem sido o eixo principal das novas estratégias de crescimento e desenvolvimento sustentáveis, que permitem melhorar a qualidade de vida das populações (PORTUGAL, 2017).

A importância da ciência para a sociedade é inquestionável, uma vez que possibilita avanços nos diversos campos do conhecimento, enriquecendo as sociedades intelectual e culturalmente. Os desafios impostos à ciência criam conhecimento, melhoram a educação e a qualidade de vida, reduzindo desigualdades e construindo pontes.

A necessidade de comunicar ciência ultrapassa, nos dias atuais, a esfera científica, culminando num quadro social de amplo acesso ao conhecimento e de estreita interação entre a comunidade científica e as sociedades.

Nesse sentido, o cidadão comum deve possuir a compreensão mínima dos processos da ciência e da tecnologia e do seu impacto na sociedade. Torna-se necessário então, fomentar o envolvimento da população e das organizações da sociedade civil na construção da ciência para o entendimento global e o desenvolvimento sustentável.

Surge então a necessidade de envolver os cidadãos nos programas científicos, fornecendo as ferramentas necessárias para fazerem escolhas informadas e conscientes. Por outro lado, os órgãos governamentais devem promover iniciativas de promoção do desenvolvimento científico, o que requer uma cooperação próxima com a comunidade científica (PORTUGAL, 2017).

A crescente especialização e consequente complexidade das ciências, dificultam sua divulgação à sociedade em geral, situação 
agravada pela postura dos gestores, que não reconhece o papel dos cientistas na sociedade e contribui para o distanciamento entre população e ciência (PORTUGAL, 2018a).

Ademais, uma vez que o desenvolvimento científico não significa de forma automática o progresso humano, torna-se crucial que a educação e formação de cientistas seja encarada de forma permanente, incluindo as dimensões éticas, sociais e políticas, no despertar de estudantes para os problemas da sociedade, desafiando-os a encontrarem soluções por meio da pesquisa aplicada (PORTUGAL, 2018a).

Os pesquisadores interessados em que um novo conhecimento provoque mudanças em determinados grupos/campos sociais, precisam estar envolvidos com tais áreas, certificando-se da eficácia dos canais de comunicação para a popularização da ciência e da tecnologia.

O cenário mundial atual aponta claramente para a relevância da produção do conhecimento científico para o desenvolvimento social.

Nesse sentido, destaca-se o potencial das Universidades, ao apoiarem ações que extrapolem os muros da academia, disseminando suas pesquisas e o conhecimento por elas gerado à sociedade.
Surge então grande desafio às Universidades em associar a ciência e a tecnologia à esfera do social, em integração harmônica também com a cultura, como forma de se alcançar uma sociedade mais humana, justa e solidária (LIMA et al., 2000).

Todos os autores declararam não haver qualquer potencial conflito de interesses referente a este artigo.

\section{REFERÊNCIAS}

LIMA, P. G.; CASTRO, F.; CARVALHO, M. A. V. Caminhos da Universidade rumo ao século XXI: pontos e estratégias para sua orientação, na visão de educadores brasileiros. Paidéia (Ribeirão Preto), v. 10, n. 18, p. 8-27, 2000.

PORTUGAL. Ministério dos Negócios Estrangeiros. Comissão Nacional da UNESCO. Ciência para a sociedade. 2017. Disponível em: https://www.unescoportugal.mne.pt/pt/temas/cienciapara-um-futuro-sustentavel/ciencia-para-a-sociedade Acesso em: 27/08/2018.

PORTUGAL. Ministério dos Negócios Estrangeiros. Comissão Nacional da UNESCO. Ciência para um futuro sustentável. 2018a. Disponível em: https://www.unescoportugal.mne.pt/pt/temas/cienciapara-um-futuro-sustentavel Acesso em: 27/08/2018.

PORTUGAL. Ministério dos Negócios Estrangeiros. Comissão Nacional da UNESCO. Construir sociedades do conhecimento. 2018b. Disponível em: https://www.unescoportugal.mne.pt/pt/temas/construi r-sociedades-do-conhecimento Acesso em: 27/08/2018. 